\title{
Climate Change as Ecological Colonialism: Di- lemma of Innocent Victims
}

\section{Prakash Upadhyay}

\begin{abstract}
Climate Change is at just the once a social, cultural and an ecological issue. It is an environmental justice issue, an issue of economic and political domination, a consequence of clash between deregulated capitalism and the welfare of mankind deeply entrenched in a capitalist economic system based upon the persistent exploitation of natural resource for individual benefits. Poverty stricken peoples of least developed countries are the innocent victims of climate change. This article argues and identifies key ways that anthropological knowledge/l ens can enrich and deepen contemporary understandings of climate change. From discussions allied to natural resource management practices it is construed that natural resource management practices are impacted from factors - political, economic (capitalism), domination, cultural, community and societal activities which are anthropogenic factors responsible for climate change calling for the equity and justice implications of climate change issues. As climate change is ecological colonialism at its fullest development-its critical scale-with sweeping social, cultural, economic and political implications, anthropological lens seek to respond to climate change at the local, regional, national, and global scales and are helpful in reflecting the understandings in application and seeking ways to pool resource with communities to assist them in addressing their climate change concerns. There are some other key contributions that anthropology can bring to understandings of climate change viz. awareness of cultural values and political relations that shape the production and interpretation of climate change knowledge, survival, power, ethics, morals, environmental costs and justice, militarism, war, intertwined crises of food, water, biodiversity loss and livelihood.
\end{abstract}

Keywords: irrevocable, bizarre rituals, defamiliarization, silver bullet, totem, human exclusion model 


\section{Preamble}

Over the past few decades Nepal has experienced a perceptible change in temperature which has put the country at risk. Climate associated extreme events such as high rainfall, shortage of rainfall (longer drought period), landslides and floods are in increasing trends in terms of magnitude and frequency. Although, the livelihood of majority of population relies on agricultural production, the land degradation has further reduced the crop productivity. The country consists of high Himalayas and hilly fragile ecosystem and regions. The disaster management strategies and health infrastructures of the country are still in infancy and they are not able to tackle the demand during the disasters created by uneven climatic events. Inadequacy of disaster management strategies and health infrastructures of the country were evident during the recent massive earthquake that rocked Nepal on April 25, and May 12,2015 that killed thousands of people and left behind thousands wounded. Vision less political leadership and political instability in nexus with climate change effects, economic and environmental degradation are preparing the ground for environmental crisis in Nepal. Climate change is anticipated to augment average temperature, rainfall and amount of precipitation that have resulted more pronounced extremes events such as droughts, flooding and outbreaks and transmissions of assortment of diseases that directly and indirectly affect human existence, health and wellbeing.

Global greenhouse gas emissions, clash between deregulated capitalism and the welfare of mankind,market-based false solutions to climate change,persistent exploitation of the Earth and all its resource to obtain super profits etc., are augmenting climate change and global warming. Earth's natural resources sustainability is imperative for tackling the intimidation of climate change and for the fortitude of humankind. Various actors and factors guarantees and hinders the sustainability of natural resource. According to Berkes and Farvar (1988) sustainability of natural resource is hindered by a variety of issues, however technological and scientific approaches to natural resource management often fail to encourage sustainable resource management because they are based on flawed models, limited goals, incomplete information, and an inadequate 
institutional foundation. Ostrom (1990) squabble that traditional natural resource management systems, in contrast, often derived over time through a process of cultural learning, are frequently successful. Hence, there is an adamant need for an assessment of indigenous resource knowledge and management goals, and better understanding of existing paradigms, social structures, political organization and knowledge dispensation in the fields of natural resource management, climate change and global warming nexus for which anthropological knowledge is crucial. Three conditions are accountable for anthropologists being caught up in climate change and global warming research to an unprecedented degree since the last many decades.

a. The irrevocable transformations that climate change is bringing to the people and places traditionally studied by anthropologists (Bokoet. al., 2007),

b. The general recognition of the importance of research on the human dimensions of climate change (Vogel et.al., 2007),

c. And the growing opportunities for anthropologists to participate in interdisciplinary climate application and adaptation research (Roncoli, 2006).

To these challenges, anthropology brings its core theoretical tenet that culture frames the way people perceive, understand, experience, and respond to key elements of the worlds which they live in. This framing is grounded in systems of meanings and relationships that mediate human engagements with natural phenomena and processes. This framing is particularly relevant to the study of climate change and global warming that necessitate movement away from a known past, though an altered present, and toward an indecisive future, since what is recalled, recognized, or envisaged rests on cultural models, norm and values. Human being and collective adaptations are fashioned by common ideas about what is believable, desirable, feasible, and acceptable by the majority. Anthropology's potential contributions to natural resource, climate and global warming researches are the description and analysis of the mediating layers of cultural meanings, norms and social practices of the majority, which cannot be easily captured by methods of other disciplines. 


\section{Objective}

The key objective of this article is to look at and illustrate the way anthropological perspectives can transact with various facades and nexus of climate change and natural resource management, social injustice and economic domination.

\section{Data and Conceptual Sketch}

This article is based on secondary data obtained from various literatures, books, journals, booklets, articles, dissertations, websites etc. The conceptual sketch of the study draws on the correlation between natural resource management pattern (inc. anthropogenic factors)and climate change nexus, and the pragmatism of anthropological lens in evaluating the connection that leads to actions from dilemma.
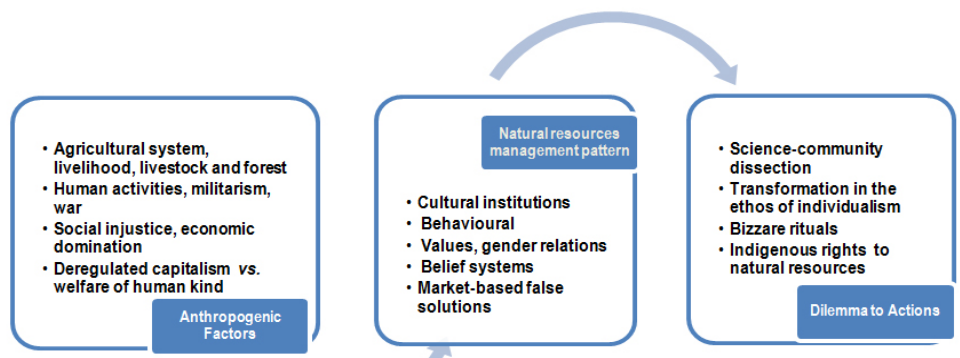

Figure 1: Climate Change and Natural Resource Management Nexus: Dilemma to Actions

\section{Anthropological Outlook on Hidden Assumptions of Natural Resource}

Anthropologists view the world with arrange of perspectives. Peacock (2001) has risen the query what is the anthropological perspective? Through what kind of lens does the anthropologist view the world? He inquires does anthropology have just one lens -a single perspective? He forwards the answer that there are as many perspectives as there are anthropologists. The Anthropological Lens throws Harsh light but Soft Focus. Based on photographic metaphors of "harsh light" and "soft focus" anthropological world 
view of harsh light denotes a concern with basic reality of human condition, soft focus attempts to grasp all aspects of that condition. Despite multiple perspectives, the four main anthropological perspectives which make anthropology unique among the social sciences includes its:

a. Cross-cultural or comparative analysis,

b. Evolutionary/historical emphasis,

c. Ecological emphasis and

d. Holistic emphasis.

Cross-cultural or comparative approach avoid equating human nature-not taking belief or style of behaviour of managing resource for granted in present, studying other cultures with very different understandings of world called defamiliarization. Evolutionary/ historical approach focuses on both biological and cultural evolution of human beings and of human societies-- diachronic that focus upon understanding of and description of patterns of change over time including Natural Resource Management (NRM) and climate change that helps to put existing society and social development into an historical context. Ecological anthropology views human societies within the context of larger natural systems- how culture promotes connections between humans and their occupied ecosystems.

Holistic approach closely related to ecological approach focus on human behaviour, society-- incorporating ecology in a significant/integral way with human life, belief that cultures have its own pattern of adaptation to natural resource, stages of adaptation based on major subsistence patterns. Embedded with these vital theoretical perspectives, there are three vital dimensions: the cultural, the institutional and behavioural. The first of these dimensions defines values and expectations concerning resource and environment evolving in any population; the second, the means and ends of key activities; the third, the distinctive patterns of individual need, satisfaction and coping mechanism. Cultural dimensions reckon that natural resource are socially, culturally ingrained values of community intertwined with human life, behaviour, response and way of living, hidden assumptions embedded with social, cultural, cognitive systems rather than technical factors that are secretly 
playing key role in decisively shaping natural resource management pattern. Institutional dimension holds that resource user's local approaches and skills, founded on traditional cultural concepts of social/cultural institutions act in response to increasing pressures/ opportunities in a complex world of commercialization, competition, privatization, westernization of culture and increasing globalization. Behavioural dimension brings its core theoretical tenet that culture frames the way people behave, perceive, understand, experience and respond to key elements of the worlds which they live in grounded in systems of meanings and relationships that mediate human engagements with natural phenomena and processes. This framing is mainly relevant to the study of climate change and global warming that call for progress away from a known past, though an altered present, and toward an indecisive future, since what is recalled, recognized, or envisaged rests on cultural models, norms and values.

Holism is the assumption that no complex entity can be considered to be no more than the sum of its parts, that any given aspect of human life is to be studied with an eye to the way it is / related/ to other aspects of human life. Holism is a synonym for a relational emphasis; an emphasis upon studying the /relationships/ among all aspects of culture-rather than whole cultures. Knowing anthropological facts and weaving them into a coherent synthesis, one still does not grasp the full meaning of the anthropological perspective unless one comprehends cultural significance. One does not grasp the full meaning of the anthropological perspective unless one comprehends cultural significance of any phenomenon. Culture is a part of a broad view of human existence that anthropologist term holistic. If the holistic field of vision of anthropology is extended far enough, it would include the perceiver as well as the object perceived, and this too is a concern of anthropology, which recognizes the subjective as well as the objective aspect of knowledge, human behaviour, cognition and social cultural values that are vital in determining the status of natural resource as they are not only woods but are socially and culturally defined values of local community intertwined with human diverse behaviour and response. 
The holistic vision of anthropology is linked to cultures. Bennett (1966) claims that anthropologists use the term culture to refer to distinctive life styles associated with particular groups of people. Going according to this, each culture must be considered to have its own pattern of adaptation to the physical environment. These could, in turn, be classified into types or stages of adaptation based on major subsistence patterns: hunting and gathering, pastoralism, settled agriculture, and so on....Within the social sciences, at least, three important dimensions ought to be studied : the cultural, the institutional and behavioural. The first of these defines values and expectations concerning resource and environment evolving in any population with relative social unity; the second, the means and ends of key activities; the third, the distinctive patterns of individual need satisfaction and coping mechanism.... One must know about institutions and precedents in order to determine why people do what they do in particular times and places. The concept of adaptation is central to the human use of the physical environment. It is the change in modes of behaviour designed to manage or improve a lot of the individual and the group. Any change in adaptive patterns in groups usually involves a collective decision. That is adaptation at group level is coincident with social action, interaction, dynamics of social organization and change. There is the vitality of social values, institutions and norms/traditions in regulating environment, indispensability of norms, customs, and traditions in influencing resource user's behaviour on natural resource.

According to Colby (1996) Cognitive anthropology known as ethno science, ethno semantics focuses on the native's point of view--- how people in particular cultures classifies the world including their natural resource. Originally, it is based heavily on how local people use expressions to codify reality in emic (internal) idealist approach to culture. Here culture is defined as a body of knowledge in people's heads --a mental model, map, or maze way. Thought is culturally shaped while making use of natural resource, not just psychological---people learn to think in certain ways in each culture and each culture is determined by the Indigenous knowledge which is the traditional knowledge of the local people that has been continuing from centuries and which 
has been given little attention in development planning's based on western knowledge. Sillitoe (1998) asserts that Ethno conveys a special sense--the system of knowledge and cognition typical of a given ethnic group/community signifying the local knowledge of local people, local people's hidden concepts on natural resource.

The concealed (hidden) assumptions about culture are embedded in human cultural discourses and resource management institutions. Such assumptions are like lenses-they shape how people perceive social reality. As scholars and managers for anthropologists who are trying to understand conflicts in resource use, it is important to make these lenses visible, that is, to look at a society's cultural lenses rather than through them, to acknowledge, understand, and question the assumptions we have about cultural milieu and its embeddedness with nature. One important point central to this issue is an understanding of the lenses of Culturocentrism that is, taking the dominant culture's experience as the norm, and other culture's experiences as deviations or "other". Also informative are ideas concerning culture polarization, that is, the insidious use of perceived differences in culture as an organizing principle for natural resource management. Messerschmitt (1991) provided a framework for the study of IK (Indigenous Knowledge) and illustrates it with numerous examples from forestry research in Nepal. The framework is divided into two parts. First, he discusses the collection and understanding of basic IK. This part provides information on the nature of indigenous forest knowledge, which holds the knowledge, where and how the knowledge can be accessed, and what the knowledge means to the people who have it. The second part focuses on the application of IK: i.e. the link between resource management and ethno-knowledge. Gilmour and Fisher (1991) cite different examples to show that over time indigenous knowledge adapts to changing social, economic and environmental conditions.

Right through different ethnic groups there is a cognitive consonance or consistency among the beliefs, ideas, perceptions and other items and aspects of knowledge that form a cognitive system such that the system stands as an integrated and harmonious whole without internal contradictions. Identical with it is the tendency 
of individuals to include among his cognitions those items of knowledge that are in agreement with his beliefs, attitudes, values, and needs and to exclude those that are not. Selectivity occurs in perception, interpretation, and remembering. It is this knowledge, which can be better used for handling various sorts of environmental related natural disasters, climate change and global warming. The effect of disasters depends on the spatial and temporal distribution of population. Given the nature of planet, it is rather difficult to control hazards in actual processes. The solution to plummeting disaster and their impacts is thus to focus on decreasing vulnerability and promoting prevention. The latter can be achieved to some extent by incorporating local knowledge and initiatives into the framework of public policy and decision- making.

Natural resource management practices not solely economic, administrative, bureaucratic and technical activities, it is also more than sharing of benefits. However, it is intensely embedded in an economic system based upon the persistent exploitation of natural resource to obtain super profits for a small minority of rich people. There are different social and cultural factors tangled with natural resource management practices. It is impossible to disregard the reality that hidden assumptions about culture are embedded in one's cultural discourses and resource management institutions. These hidden assumptions determine how local people perceive their natural resource, manage, control and develop coping mechanism to fight the menace of climate change in the long run. Going against these, means inviting confusions, conflicts and problems, such as deforestation, environmental deterioration, climate change and global warming. Berardi (2002) argues that for the scholars and managers who are trying to understand conflicts in natural resource use, it is vital to make the anthropological lenses visible. It means to look at a society's cultural lenses rather than through them. Such lenses are relatively easy to see in relation to gender and social/cultural relations/activities which are vital in determining the providence of natural resource management practices, climate change and global warming nexus. Acharya \& Bennett (1981),stressing on gender variation in decision making amongst different communities of Nepal, has claimed that there 
is predominate role of men in Maithili and among Rai the role of female is predominate in decision making in all activities including natural resource management.

Anthropological Perspectives on Climate Change and Global Warming

The issue of climate change is more anthropological than environmental or economic. There are vital key contributions that anthropology brings to understandings of climate change. Human and ecosystem interactions have been a decisive dimension of anthropological theories of what drives culture and behaviour. Climate change is about culture with cultural insinuation, more of the intimate human-environment and nurture-nature relations. Culture is a flexible contingent to the environment with a social unit's characteristics (technology, politics, and modes of subsistence etc.) having adaptive limitations. The awareness to the cultural values and political relations figure out the production and interpretation of climate change knowledge and shape the basis of responses to ongoing environmental changes.

An understanding of the historical milieu that underpins contemporary climate change and global warming debates is vital. This awareness stems from the interest of both archaeologists and environmental anthropologists in the history of societyenvironment interactions. Anthropology's broad, holistic view of society and environment, natural resources highlights the multiple cultural, social, political, and economic changes that are taking place within human society. The political anthropology's concern is for understanding the political factors, policies and implications on climate change. Such dynamics always interact with, and sometimes outweigh climate change as sources of change and need to be understood if public policies are to succeed. I deem that incorporation of anthropological logic mainly (cultures and customs) can lead to a more nuanced understanding of the challenges that climate change poses and to more effective solutions. Creativity, adaptability, and flexibility are basic human attributes, and human diversity is the subject matter of anthropology hence knowledge is holistic pertaining to the study of the whole of human condition: past, present, and future; biology, society, language, culture, natural resources use pattern etc. 
Anthropology has two dimensions: general and applied. The applied uses anthropological perspectives, theory, methods, and data to identify, assess, and solve social problems including the natural resource management pattern, climate change and global warming. From an anthropological perspective, there are cultural implications of climate change. Climate change is eventually about culture, for in its wake, more and more of the intimate human-environment relations, fundamental to the world's cultural diversity. For indigenous peoples in the regions of the world, climate change brings different kinds of risks and opportunities, threatens cultural survival and undermines indigenous human rights. The consequences of ecosystem changes have implications for use, protection, and management of forests, wildlife, fisheries affecting the customary uses of culturally and economically vital species and resource.

The effects of climate change are not just about communities' or populations' capacity to adapt and exercise their buoyancy in the face of exceptional change. Climate change is furthermore about the relocations of human, animal, and plant populations to adjust to change and to muddle through with its implications. Such relocations, both actual and projected, necessitate a loss of intimate human-environment relationships that not only ground and substantiate indigenous world views, but also work to maintain and guard local landscapes. In some cases, moves end result is the loss of mythological symbols, meteorological orientation and even the very totem and mainstay plants and animals that shape a culture. Indigenous peoples themselves may argue that, despite having contributed the least to greenhouse gas emissions, they are the ones most at risk from its consequences due to their dependence upon and close relationship with the environment and its resource. Their livelihood systems are often in danger to environmental degradation and climate change, especially as many dwell in economically and politically marginal areas in fragile ecosystems in countries likely to be worst affected by climate change. Massive changes in ecosystems are occurring and have in many cases been accompanied by opportunistic and often environmentally devastating resource exploitation. To indigenous peoples this means that climate change 
is not something that comes in isolation; it amplifies previously existing problems of poverty, de-territoriality, marginalization, and non-inclusion in national and international policy-making processes and discourses. Indigenous peoples in Asia and Latin America are facing rapid and overwhelming changes in their societies and livelihood strategies, making them mainly vulnerable to climate change, poverty and other forms of marginalization and exploitation. ILO (International Labour Organization) convention No. 169 recognizes the survival of indigenous peoples - as distinct peoples - largely depends on the sustainable utilization of their traditional lands and natural resource in a manner and mode appropriate to their specific circumstances and survival.

Overtly or covertly human activities alter the composition of the global atmosphere and which is in addition to natural climate variability observed over comparable time periods. But, there are copious uncertainties in understanding a complex system like Earth's climate. Crate and Nuttall (2009) squabble that the term climate change is the contemporary phenomena of anthropogenic global climate change, as distinct from natural climate variability. It may not be just a temperature, but also includes factors such as humanity, precipitation, cloudiness, and winds. The variations in climatic parameters are attributed directly or indirectly to human activities. It is escalating the hazard of deforestation, flooding, storms, desertification, soil erosion, and sea level rise contributing to international and national migration with the experiences of privation, loss of jobs and homes, and the fragmentation of families, communities and different types of social, cultural and political upheavals. Hence, the impact of climate change is not consistent across the globe, and considerable differences can be perceived between different regions, places and communities. The impending risk of vulnerability to climate change is expected to be high in mountains and coastal areas and the island countries (Dessler \& Parson, 2006). Carbon dioxide $\left(\mathrm{CO}_{2}\right)$ is a vital heat-trapping (greenhouse) gas, which is released through human activities as deforestation and burning fossil fuels, as well as natural processes as respiration and volcanic eruptions. 
Rural native people's cultures worldwide are at the clemency of climate change. Local infrastructure and material culture - those tangible aspects of culture such as artifacts, architecture, and art are constructed with locally-available natural resource now being threatened. It is also doable that non-tangible facets of culture such as customs, stories, myths, and songs, as well as entire languages tied to a culture's place of origin, will face extinction. This is owing to the possibility of increasingly uninhabitable rural locations forcing members of rural cultures into urbanized environments, thereby breaking ties to homelands. The threat is not so much a consequence of indigenous peoples' inability to acclimatize to disturbances in climate, but rather their vulnerability to such rapid changes to which adjusting would require much more time for preparation and less frequency between turbulences. Dessler and Parson (2006) argue that 'climate change' does not just affect people directly; it also affects all other environmental and ecological processes, including many that we might not recognize as related to climate change.

The risks of climate change for least developed Nepal can hardly be exaggerated and communities, governments and other institutions have lot of functional challenges to minimize the adverse effects of climate change. Upadhyay (2007) reveals that there are credible bodies of substantiation based on various researches on Nepal that climate is changing and that these changes are in large part caused by human activities with cultural implications. The cultural implications could be similar to the disorientation, alienation, and loss of meaning in life that happens when any indigenous people are removed from their environment of origin owing to impacts of climate change. With the change in environment, it is vital to comprehend the cognitive impact and cultural implications to a people's sense of native soil and place. The relationship of native communities with local resource, livelihood along with their socioeconomic characteristics and climate change stands imperative. With the increasing deforestation many of the indigenous groups such as the Rautes in Nepal are confronting with food scarcity and are moving away from their traditional homeland. Dahal (1983) argues that it is vital to understand the socio-economic and demographic characteristics of a community in relation to its available resource. 
Maharjan (2005) bicker that being an economically less developed agricultural country, the relationship between Nepalese agricultural system, livelihood, and livestock and forest remains crucial, hence a nexus prevails between natural resource management pattern and climate change.

Temperature and rainfall are two key climatic factors affected by climate change and global warming which is rapidly advancing creating widespread threat. Anthropogenic factors -deforestation, agriculture, industries, automobiles emissions, burning of fossil fuels etc. are causative to GHG (Greenhouse Gas) emission which is the foremost cause of global warming and rising temperature that is creating different problems on ecosystems and biological behaviors of different species. Himalayan glaciers are mostly susceptible to changing temperatures. Shrestha et. al. (1999) squabble that warmer temperatures cause accelerated melting of glacial ice, resulting in shrinkage of glaciers leading to the formation of glacial lakes, some of which may burst out and cause flash floods known as glacial lake outburst floods (GLOFs) downstream in the valleys. Khumbu glacier in Nepal has retreated about $100 \mathrm{~m}$ on average annually since 1953.

Cruikshank (2005) draws some important lessons for the pursuit of defining anthropology's role in climate change. Specifically she emphasizes how glaciers, previously considered eternally frozen, largely inert, and safely distant, gain new meaning in the context of contemporary climate change concern. Cruikshank stresses how glaciers undergoing rapid environmental change are interpreted differently. In the Andes, a long-held ritual practice involving pilgrims carrying pieces of glacier away has recently stopped to prevent the glacier's diminishing. There are contrasting approaches to understanding climate change and they all deserve attention and consideration as we approach strategies and solutions. Climate change exacerbates existing social, economic, political, and environmental trends, problems, issues, tensions, and challenges and hence increases vulnerability of different regions. Different districts of Nepal are at high risk to climate change consequences including capital Kathmandu. 
Table 1: Vulnerability Ranking of the Districts of Nepal

\begin{tabular}{|l|}
\hline VULNERABILITY RANKING DISTRICTS OF NEPAL \\
\hline Very high (0.787-1.000) : Kathmandu, Ramechhap, Udayapur, Lamjung, \\
Mugu, Bhaktapur, Dolakha, Saptari, Jajarkot, Mahottarai, Dhading, Taplejung, \\
Siraha, Gorkha, Solukhumbu, Chitwan, Okhaldhunga \\
\hline High (0.61-0.786) : Achham, Manang, Dolpa, Kalikot, Khotang, Dhanusha, \\
Dailekh, Parsa, Salyan, Sankhuwasabha, Baglung, Sindhuli, Bhojpur, Jumla, \\
Mustang, Rolpa, Bajhang, Rukum, Rauthat, Panchthar, Parbat, Dadeldhura, \\
Sunsari, Doti, Tanahu, Makawanpur, Myagdi, Humla \\
\hline Moderate (0.356-0.600) : Bajura, Baitadi, Bara, Rasuwa, Nawalparasi, Sarlahi, \\
Sindhuplachok, Darchula, Kaski, Nuwakot, Dhankuta, Kanchanpur, Bardiya, \\
Kapilbastu, Terathum, Gulmi, Pyuthan, Surkhet \\
\hline Low (0.181-0.355):Argakhachi, Morang, Dang, Lalitpur, Kailali, Syangja, \\
Kavrepalanchok \\
\hline Very low( 0.000-0.180): Ilam, Jhapa, Banke, Palpa, Rupandehi \\
\hline
\end{tabular}

Source: MOE, 2010

Aggravating yield due to adverse weather and climate lead to vulnerability in the form of food insecurity, hunger and shorter life expectancies and poor will again be the victim. Hydroelectricity accounts for 9 percent of total power production in Nepal, hence Nepali people living in different parts will have to face problems of severe electrical power-cut due to sediments carried along the floods. By making use of anthropological lenses not only in local context but on the scale of global geopolitics, anthropologists can perceive the causes and effects of climate change to be about people and their life, power, ethics and morals, environmental costs and justice, and cultural and spiritual survival. Addressing the issues of equity and justice implications of climate change seems imperative. Climate change is proving to be an ecological colonialism with extensive social, cultural, political implications, the result of global processes that were neither caused nor can be mitigated by inhabitants of majority of climate-sensitive regions now experiencing the most unprecedented change. Native peoples and place-based peoples find themselves at the mercy of and having to adapt to changes beyond their control. 


\section{Climate Change and Global Warming as Ecological Colonialism and Dilemma of Innocent Victims}

Capitalism has become universally accredited global economic strategy. Upadhyay (2007) argues that except racial discrimination, colonialism,wars, imperialism, exploitation, and inequality, the capitalist industrial world has done much to make better human life in the last two centuries but now that same economic systems' industrialization is threatening life on Earth. Embedded with colonialism, it took capitalism over six hundred years to get to where it is now, including the colonial theft of three-quarters of the world and the degradation of its peoples, hundreds of years of slavery, segregation laws, gross inequality, wage-theft, suppression of women, child labor, the holocaust imposed upon Native Americans, two World Wars, thousands of nuclear weapons ready for third world war, monstrous poverty on Earth today, and prophecies of much shoddier environment changes with each passing decade. The price of capitalist progress has been very severe on humanity. Another price, if mankind allows it to happen, is severe climate change for future generations that will bring all to peril.

The impacts of climate change are being experienced by millions in the world's most vulnerable and marginalized communities. Climate change has turn out to be a clash between deregulated capitalism and the welfare of mankind. United States is among the small minority of countries that have refused to ratify the basic United Nations document on climate change, the Kyoto Protocol. United States, Western powers and China are accountable for climate change to a great extent. U.S. is historically responsible for the lion's share of global greenhouse gas emissions. The problem is deeply embedded in a capitalist economic system based upon the persistent exploitation of the Earth and all its resource to obtain super profits that largely accrue to a small minority of people. Communist China is the world's largest annual contributor of $\mathrm{CO} 2$ to the atmosphere which is devoting the greatest amount of resource and money to develop sources of green energy, but the gap between its fossil and renewable fuels is immense. The U.S. military is the largest single emitter of carbon. The U.S. and the World Bank (in which the U.S. has de-facto veto decision-making 
power) dictate the discussion of what to do about global warming with market-based false solutions.

Given their wealth and powerful status as global hegemonic, the powerful countries have been the principal obstacle to concerted global climate action. The large-scale, ecologically and socially devastating corporate-controlled false solutions to climate change that currently dominate the conversation must be eliminated. Anthropologically, addressing climate change will necessitate a fundamental restructuring of human society that, if thoughtfully done, can put down a new base that will concurrently help achieve both global justice and ecological balance. Solutions to climate change will not be controlled by big powers and corporations. They should be small in scale, locally controlled, decentralized, bioregionally appropriate and socially just. Climate Change is at just the once a social, cultural and an ecological issue, environmental justice issue and an issue of economic and political domination hence to productively address the climate crisis, it is indispensable to identify and address the unfathomable root causes that link it to the myriad other crises humankind face- social, economic, militarism and war, as well as the intertwined crises of food, water and biodiversity loss etc. These crises are unified by their common roots in an economic system that encourages multinational company and corporations to ignore ethical and moral considerations and gamble with the Earth, peoples' lives, and collective human futures in the service of higher economic profits. There is no single silver bullet solution. It is vital to concentrate on the common root causes of ecological destruction, social injustice, and economic domination, ignorance of natives' cultures and traditions and the interconnection of these issues with climate change.

In many regions of the world indigenous innocent peoples have been heedful stewards of their ancestral lands but now these biodiverse and rich lands are now being coveted by the World Bank, multinationals conglomerates and governments. Massive land grabs are taking place to privatize vast expanses of land where legal ownership is unclear or has not been established. These lands are prized for the rich resource they contain, for the development of agrofuel feedstock's or monoculture tree plantations; and for 
the vital role they can play in offsetting carbon emissions. World Bank's Forest Carbon Partnership Facility (FCPF) scheme threatens to relocate resident communities under the semblance of protecting the forests so that the carbon they absorb can be used to compensate emissions in the North. This environmental protection based on human exclusion model has been perfected over the years by the likes of Conservation International and the Nature Conservancy. Divergent to this colonial model, however, one of the steps toward truly addressing climate change must be to give indigenous peoples an autonomy and full control over their ancestral lands and their natural resource which will be then the real adoption of anthropological philosophy that will possibly lead natives from quandary to achievement. Anthropological lens are manifold but crucial in studying the impacts of the science of climate change and structured climate change refutation on popular understandings of global warming. How is climate science disseminated and received by global viewers, through which channels, and with what effects? What facets of climate science appraisal are adopted and integrated with local knowledge and under which conditions? Anthropologists treat climate science as a communicable object and surmise that the price of capitalist progress is very harsh on humanity. It deem that climate change crises are unified by their common roots in an economic system that yearn forgetting higher profits by inexorable exploitation of natural resources, ignore ethical and moral considerations and gamble with native peoples' lives. By the use of anthropological lenses on global geopolitics, anthropologists perceive causes and effects of climate change to be about people, their life, power, domination, political economy, ethics, morals, environmental costs, justice, cultural-spiritual survival, equity and justice. Societal transformations often correspond with climatic alterations, although shifts in climate systems do not always result in significant changes in society. One of the remarkable impacts of climate change is on the people of the world, as changes in climate have both facilitated and restrained human geographic movement. Additionally, climate has played a role in the collapse of social systems and contributed to the limited human use and reconstruction of physical environments, allowing subsequent re-occupation. 
Anthropological connection is vital in appraising the social origins of climate change in light of the intensification of global economic system's dependent on profit-making and unequal distribution of wealth, continual resource-depletion, and mounting waste producing economic expansion. This issue too is beyond climate science in that how human societies perceive and treat their environments, how they organize their use of energy, and the systemic drivers of massive quantities of greenhouse gas production and emission are embedded in social not environmental systems. This recognition has drawn anthropologists to debates on issues like societal collapse and even to the topic of economic collapse on a splendid scale. Anthropologists have commenced to draw attention to the interaction of climate change with a substantial list of other anthropogenic environmental transformation and ecological crises. Rather than a separate threat, global warming is but one of multiple consequences of human restructuring of earthly ecosystems and wealth especially natural resource and unregulated capitalism.

Anthropologists are active in documenting the special challenges, lived experiences, local knowledge, and perceptions of contemporary anthropogenic climate change in human communities, especially in developing settings that are hardest hit but least involved in the production of greenhouse gases. They are appraising concepts like hazard, vulnerability and resilience in examining the sustainability of local ways of life and resource utilization. Among medical anthropologists, a topic of apprehension is the health implications of global warming, including its impacts on the spread of vectors, flooding tied to sea level rise and melting glaciers, windblown soils and microbes, and the infrastructural damage to healthrelated resource of climate change. Anthropologists are working on identifying the assortment of factors that influence how and why communities react as they do to climate change, including initiating adaptive responses, politically organizing to demand striking slash in global greenhouse gas emissions, seeking outside assistance to adjust to growing threats, fleeing deteriorating conditions, and expressing a lack of capacity to take action meaningfully to changes that are occurring. All of these issues are outside the domain of expertise of other sciences and involve issues of culture and social structure. 


\section{Dilemma of Innocent Victims of Climate Change: A Case of Central Nepal}

This case is from Simjung Village Development Committee (VDC) of Gorkha district of central Nepal. Simjung is situated in the foothill of Manaslu Himal. The total population of Simjung VDC is 3715 with a total 841 households. The total female population of this VDC is 1978 and the male population is 1737 (CBS 2012). Farming is a primary source of income of the people in the area. This VDC is the mosaic of diverse cultures, language, and natural resources. This area is rich in terms of ethnicity and the population of female is relatively high but the literacy rate of female is very low, compared to male. Gautam (2015) argues that this area is preeminent for exploring climate changes impact because geology of the area is very fragile with frequent events of landslides, natural disasters and unpredictable blizzard.

Climate change was observed by the Simjung people since the last many years in the form of decreased rainfall, blizzard at inconvenient time etc. The amount of the monsoon rains had decreased and the set off of the rain had become unpredictable. While considering the monsoon rain now as compared to last 30 years, the amount of monsoon rains has decreased which was observed from last 20 years and the start of the rainfall was not predicted from last 10 years. Climate variability has played a vital role in declining crop yield, increasing the landslides and other natural calamities. People of Simjung have adapted this change by re-scheduling their agricultural calendar--planting the crops earlier and later, changing crops types etc. People and livestock also suffered various diseases due to the variability in rain and blizzard fall at inconvenient winter time. For coping diseases induced by climate change, people have started using pesticides and more fertilizer in farming and also spend the savings for medicine in buying pesticides which has increased their economic burden.

From this case experience, it is deduced that managing climaterelated risks to agricultural production necessitate new information, skills and technologies such as seasonal forecasts, risk analysis and water saving agricultural practices. Men in Simjung are more likely to have access to these resources, the knowledge and the power to 
use them, and are therefore better equipped to adapt. Women often have traditional indigenous knowledge that can inform adaptation efforts. Old and new information can be important in adapting. This case study findings avow that processes of climate adaptations can include element of activism for gender equality however due to unequal gender relations, women's responsibilities and roles are often overlooked or taken for granted. Equally, human vulnerability is affected by human interactions with social, economic, political, and environmental events and processes. Nevertheless, common people especially women are the innocent victims of climate change effects.

\section{Dilemma to Actions}

Climate change result has become a part and parcel of people living throughout the countries of the world. Native poor people of least developed countries are the naive victims of climate change. To a great extent ravenous human behaviour is the root cause of predicament. Hence, ethnographic knowledge dissect the making of climate science as an arena of human behavior enlightening the ways the wider political environment, including aggressive climate change denial campaigns in developed countries, have caused climate scientists to be observant in their presentation of their findings to public audiences. The key dilemma is communicating with both masses and policy makes in culturally meaningful and effective ways. Anthropological lens are vital in investigating the social origins and economic motivations of climate change rejection and the social ideologies and motivations of climate change rejectors. Given the triumph of the rejectors in embroiling confusion about global warming and in holding up meaningful policy responses to crises, gaining a clear understanding of climate change denial and dissemination of knowledge is of critical significance for anthropologists. For anthropologists, adaptation is mainly about warning people about certain events in advance and preparing them to deal with vulnerability and uncertainty. Increasingly, anthropologists are encountering the local effects and broader social, cultural, economic, and political issues of climate change. Wherever they go and work, they encounter local people 
(who are the worst victim) telling similar accounts of the changes they notice in the weather and climate and how they became the innocent victim of climate change-paying for the consequences of the blunder committed by Others (big powers) at global level.

Anthropological lens respond to climate change at the local, regional, national, and global scales and are helpful in reflecting the understandings in application and seeking ways to collaborate with communities to assist them in addressing their climate change concerns or in bridging the science-community dissection with a notion that climate change issues have to be dealt, comprehend, and resolved within a context of the interplay of multiple stressors at all levels--local to global, national to international. Human activities, industrial development, consumerism, resource-use regulations, and global economic processes have far-reaching consequences for the environment and on indigenous and local livelihoods. Native and local economies are not self-reliant blocked systems, and although their involvement in global networks of production and consumption may offer opportunity to strengthen and extend their possibilities, it also introduces greater elements of risk and perhaps makes people and their livelihoods less durable to coping with and adapting to climate impacts.

For some people, climate change may not be the most immediately pressing issue facing them. Social, cultural, and economic change often has more immediate effects. Communities differ in the way they perceive risk, in the ways they utilize strategies for mitigating negative change, and in the effectiveness of local adaptive capacity. The impacts of climate change are speeding up the adoption of different subsistence and local economic strategies to suit new ecosystem regimes or, with more rapid change, the displacement and resettlement of peoples who risk at risk or even losing their homeland to environmental change. While muddling through climate change menace, there are diverse bizarre rituals that are common among the farmers of Nepal as different beliefs exist among them. According to Bhandari (2005) among the Tharu community on the bank of the Babai River near Gularia, during the prolonged drought conditions they perform bizarre rituals. During the rituals Tharu women plough their house yard in a reverse manner 
at night singing song to appease rain god when dry spells persist too long effecting agriculture. Husbands are blindfolded, and if any of them are peeping, they are punished and fined foodstuff, which is again offered to the rain god. The punishment may also include the dressing up of the males in female attire. Tharu communities also worship frogs as a part of the rituals. Upadhyay (2007) informs that the Tharu women of western Nepal do rain-dance to produce rain. Although there is no scientific logic of rain dance, however, it bring people together and reaffirms their faith in the collectivism, and thus the rain dance of Tharu has the function of promoting social solidarity that will help the society cope with the drought. The same prevails in the rite de passages of different ethnic groups of Nepal and other countries. The month of Shrawan (July-August) is not the right month for marriage in Nepal; however, Adhikari (2009) reports the marriage ceremony of frogs at Sijuwa in the Morang district as the farmers in the region were worried due to the total absence of rain. Invitation card was distributed to about 1500 persons for the marriage ceremony of Meghnath from Kohabara to Sulochana from Sijuwa. The ceremony was complete in all respect conducted by a priest that was held on the fourth of Shrawan. The male frog was named Meghnath meaning 'lord of cloud'. Sulochana is the wife of Meghnath in Purana, a Hindu epic. The report, however, does not provide information whether the rituals was a success or failure to appease the rain god. Local institutions are effective/legitimate means of controlling and regulating climate change. Gurung (1996) argues that there are various socio-cultural practices commonly known as riti-thiti systems among the Tarami Magarof Western Nepal. Socio-cultural practices are effective/appropriate for managing local resource in the changing context of climate change. The influence of religious beliefs and rituals give rise to appropriate institutions and organizations for cooperative resource management and provide messages and symbols for nature conservation.

Climate change has got ultimate and historical to present direct interrelationship with human culture having impacts on culture, ways of life, spirituality, and in other arenas that are not obvious. Pedestal on anthropological lenses it is overtly perceptible that climate and cultural milieu and society are inextricably linked, as 
opposed to the traditional natural science approach that does not deal with humans. Local people's experiences range broadly from erratic weather patterns, ecological variability and their bad effects on human health. However, globally local people are still not quite sure whether the changes are due to climate change or some other reasons. Effective perceiving, understanding, experience, and response, predictability, awareness, provision of certain support systems and better planning are some of the key issues to consider in local preparedness for reducing vulnerability and enhancing resilience.

According to Roncoli et.al. (2006) culture frames the way people perceive, understand, experience, and respond to key elements of the worlds which they live in. It is needed to be attentive to considerations of human agency and different responses and strategies in any one particular locality, as well as to local and regional scales, organizational complexity, ideology, technology, and social and cultural values of local populations within an interregional context. The cultural framing is grounded in system of meanings and relationships that mediate human engagements with natural phenomena and global political processes. Crate (2009) argues that civil society and self-advocacy (including anthropologists) are somewhere playing proactive roles as communicators by seeking out the local, regional, and national channels through which local voices can affect any forms of policies. Here, the notion of the construction of social reality and the embeddedness approach, in understanding and analyzing individual human behaviors, their institutions, human-environment relation, micro-macro structural relations, and others, is important part of resolving the discrepancy between agency and structured based approaches. It means the understanding of the concept emphasizes the needs of understanding social networks patterned in the dynamics of human and institutional interactions. He further says that people in communities talk to each other and to outsiders about particular risks, and that is what creates their meaningful, action-prompting perceptions on the budding risks of climate change that is caused by the multiple drivers of global consumer culture, transforms symbolic and subsistence cultures, and will only be forestalled via a 
cultural transformation from degenerative to regenerative consumer behavior. The human agency and their adaptability in changing context are to develop their own sense of impact of climate change in human societies. The variation of the size, scale of organization, social differentiation, subsistence activities, productive strategies, ideologies, and world views play vital roles in this regard. The way how they are maintained, reproduced, and transformed as a result of the impact of day to day practices by individuals who are constrained by their perceptions, beliefs, norms, values and mind sets as cognitive schemata and are outcomes of their either positive or negative perceptions.

There are immediate and long-term consequences of climate change and the existing attempt at greening of politics of remedying the potential catastrophic consequences aim to remedy the shortsighted modus operandi of societies. A long term vision will be more effective for tackling the menace. The relationship of local communities with local natural resource, biodiversity, and livelihood along with their socio-economic characteristics stands vital. When the particular community has access to information about how climate change is affecting their lives, often in tandem with seeing changes to their lands, then they act accordingly against the impacts in their life ways. Crate and Nuttall (2005) argues that the adaptation to extreme climate events will be a measure of ability or inability of individual, household, and communities to make decisions that allow them to respond effectively and with a degree of autonomy. He further argues that it is challenge to understand climate change within a broader context of political processes and ambition, cultural specificity, and people's epistemological, social, cultural, economical and moral relationship with the environment. The arguments of Puntenney (2009) may be interconnected herewith. He notes that upon closure examination of the issues surrounding climate change, we know by definition that the outcomes of international debates are the result of complex interactions of many factors, including sudden changes in the global environment or scientific understanding, macroeconomic trends, domestic and international political environments, and the presence or absence of effective leadership. Bohren (2009) stressing on 
the car culture in United States concluded that transformation in the ethos of individualism, personal freedom, and mobility away from reliance on the car as cultural challenge of technological and behavioral components of emission reduction. The query is how discourses of global climate change politics interrelated with local socio-economic dynamics and discourses.

\section{Finale}

Solutions to climate change will be many. However, there is no single silver bullet solution. Successfully addressing climate change will require a fundamental restructuring of human society that, if thoughtfully done, can lay a new foundation that will simultaneously help achieve both global justice and ecological balance. They should be small in scale, locally controlled, decentralized, bio-regionally appropriate and socially just. As climate change is an environmental justice issue and an issue of economic and political domination it has proved to be a clash between deregulated capitalism and the welfare of mankind. The problem is deeply embedded in a capitalist economic system based upon the persistent exploitation of the Earth and all its resource to obtain super profits that largely accrue to a small minority of people. Poor inhabitants of poor countries are the worst victim of climate change effect who are the innocent victim-paying for the consequences of the blunders committed by big powers at global level. Making out the challenge that climate change poses and the crafting of appropriate adaptation and mitigation mechanisms requires input from the breadth of the natural and social sciences. Anthropology's in-depth fieldwork methodology, long engagement in questions of society-environment interactions and broad, holistic view of society can yield valuable insights into the science, impacts and policy of climate change. Yet the discipline's voice in climate change debates has remained a relatively marginal one until now.

Climate change is ecological colonialism at its fullest development-its critical scale--with sweeping social and cultural implications. Anthropological lens seek to respond to climate change at the local, regional, national, and global scales and are helpful in reflecting the understandings in application and seeking 
ways to pool resource with communities to assist them in addressing their climate change concerns or in bridging the science-community dissection---understanding and analyzing individual human behaviours, their institutions, human-environment relation, micromacro structural relations, and others, is important part of resolving the discrepancy between agency and structured based approaches.

The patterns of natural resource management staunchly influences the climate change and global warming, however owing to uncontrolled human activities, lack of local awareness, low economic and social status, effective integrated planning and policy, it is difficult to ensure the success of climate change program in Nepal and other least developed countries. It is necessary to break this tendency, and thereby reach long lasting success in the field of climate change through appropriate strategy and use of a wide range of technical and non-technical human resource in an active collaboration with local people, developing adaptation and coping strategies with the approach which is holistic, with a strong emphasis on community participation by linking the impacts of climate change with the promotion of improved livelihood options of local peoples such as infrastructures, conservation of water sources, pasture land and community forests. This can be accomplished by providing rural people with alternative energy sources, such as biogas, solar power, and hydroelectricity and by adopting better land use management to improve carbon sinks.

\section{References}

Acharya, M and Bennett, L. (1981). The rural women of Nepal: An aggregate Analysis summary of eight village studies. The Status of Women in Nepal, 2(9). Kathmandu: Centre for Economic Development \& Administration (CEDA), Tribhuvan University.

Adhikari, S. (2009 July 7). The big 'O'. The Himalayan Times. 14. Berkes, F \& Farvar, T. (1988). Common property resource: Ecology and community based sustainable development. London: Belhaven press. Pinter publishers.

Bennett, J.W. (1996). Human behaviour: Essays in environmental and development anthropology. London: 
Transaction Publishers, U.K.

Berardi, Gigi. (2002). The lenses of culture in natural resource management (Discussion paper prepared for the cultural aspects of caring/cultural construction of nature). Bellingham: ISSRM.

Bhandari, D. (2009 July 12). Weird rituals to appease rain god. The Himalayan Times. 5.

Boko, M., I. Niang, A. Nyong, C. Vogel, A. Githeko, M. Medany, B. Osman-Elasha, R. Tabo and P. Yanda, (2007). Africa. Climate change 2007: Impacts, adaptation and vulnerability. In M.L. Parry, O.F. Canziani, J.P. Palutikof, P.J. van der Linden and C.E. Hanson, (Eds)., Contribution of Working Group II to the Fourth Assessment Report of the Intergovernmental Panel on Climate Change (pp.433-467). Cambridge UK: Cambridge University Press.

Bohren, Lenora. (2009). Car Culture and Decision Making: Choice and Climate Change. In Susan A. Crate \& Mark Nuttall (Eds.), Anthropology and climate change (pp. 370-379). Walnut Creek, CA: Left Coast Press.

Central Bureau of Statistics.(2012). National population and housing census of Nepal. Kathmandu: CBS.

Colby, Benjamin L. (1996). Cognitive anthropology. In David Levinson \& Melvin Ember (Eds.). Encyclopaedia of Cultural Anthropology (pp. 209-215).Vol. 1. New York: Henry Holt and Company.

Crate, Susan A. and Nuttall, Mark.(2009). Anthropology and climate change. Walnut Creek, CA: Left Coast Press.

Cruikshank, J. (2005). Do glaciers listen? Local knowledge, colonial encounters, and social imagination. Vancouver: UBC Press.

Dahal, Dilli Ram. (1983). Poverty or plenty: Innovative responses to population. Unpublished $\mathrm{PhD}$ dissertation, University of Hawaii.

Dessler, Andrew E. \& Parson, Edward A. (2006). The science and politics of global climate change: A guide to the debate. Cambridge UK: Cambridge University 


\section{Press.}

Gautam, Narayan Prasad (2015).Impact of climate change on gender relations: A case study of Simjung VDC of Gorkhadistrict, Nepal. Unpublished Master's Thesis in Sociology, Department of Sociology/ Anthropology, Prithvi Narayan Campus, Tribhuvan University, Pokhara.

Geertz, C. (1963). Agricultural involution: The process of ecological change in Indonesia. Berkeley: University of California Press.

Gilmour, D.A. \& Fisher, R.J. (1991). Villagers, forests and foresters: The philosophy, process and practice of community forestry in Nepal. Kathmandu, Nepal: Sahayogi Press.

Gurung, O.P. (1996): Customary systems of natural resource management among Tarami Magars of Western Nepal: Unpublished PhD Dissertation, Faculty of Graduate School Cornell University, Ithaca, New York.

Maharjan, Keshav L. (2005). Community participation in forest resource management in Nepal. Journal of Mountain Science, 2(1), 32-41.

Messerschmidt, D.A. (1991). The uses of anthropology in agro/social forestry $\mathrm{R}$ and $\mathrm{D}$ : approaches to anthropological forestry. In Wm. R. Burch\& J. K. Parker(Eds.), Social Science applications in Asian agroforestry. New Delhi: Winrock International, USA and Oxford, UK and IBH Co. Pvt. Ltd.

Ministry of Environment.(2010). National adaptation programme of action to climate change. Kathmandu: Ministry of Environment.

Nuttall, M., Berkes F., Forbes, B., Kofinas G., Vlassova, T. \& Wenzel, G. (2005). Hunting, herding, fishing and gathering: Indigenous peoples and renewable resource use in the Arctic. In ACIA, Arctic Climate Impact Assessment: Scientific report (pp. 649690). Cambridge: Cambridge University Press. 
Ostrom, E. (1990). Governing the commons: The evolution of institutions for collective action. New York: Cambridge University Press.

Peacock James L. (2001). The anthropological lens: Harsh light, soft focus.(2nd ed.). Cambridge university press, United Kingdom.

Puntenney, P. J. (2009). Where managerial and scientific knowledge meet socio-cultural systems: Local realities, global responsibilities. In Susan A. Crate \& Mark Nuttall (Eds.), Anthropology and climate change (pp. 311326). Walnut Creek, CA: Left Coast Press.

Roncoli, C. (2006). Ethnographic and participatory approaches to research on farmers responses to climate predictions. California Climate Research, 33(1), 81-99.

Shepherd. G. (1992). Managing Africa's tropical dry forests: a review of indigenous methods. Agricultural Occasional Paper 14. London: Overseas Development Institute. Shrestha, A. B., Wake, C. P., Mayewski, P. A. \& Dibb, J. E. (1999). Maximum temperature trends in the Himalaya and its vicinity: An analysis based on temperature records from Nepal for the period 1971-94. Journal of Climate, 12(9), 2775-2786.

Sillitoe, Paul. (1989). The Development of indigenous knowledge: A new applied anthropology. Current Anthropology, 39(2), 223-252.

Upadhyay, Prakash. (2007). User groups participation in community forest resource management in western Nepal. Unpublished $\mathrm{PhD}$ dissertation in Anthropology, Tribhuvan University, Kirtipur.

Vogel, C, Moser, S, Kasperson, R. and Dabelko, G. (2007). Linking vulnerability, adaptation, \& resilience science to practice: Pathways, players and partnerships. Global Environmental Change, 17(3): 349-364. 